not all the qualifications are entirely satisfactory, and thorough investigation of the field is required.

Investigation of the technical qualifications of local government officers was excluded from the scope of the recent inquiry into the qualifications, recruitment, training and promotion of such officers carried out by a Departmental Committee of the Ministry of Health under the chairmanship of Sir Henry Hadow, but the report none the less discusses a number of important factors bearing on the training of administrators competent to deal with the many important technical issues involved in local government service. While the Committee recognises the importance of appropriate technical and professional qualifications in the principal departmental officers, it points out that the functions of any chief officer of a major department are mainly administrative, and it is of opinion that, in the past, local authorities have not laid sufficient stress on the administrative qualifications.

The essential problem in local government to-day is to ensure that the service offers an attractive career for vigorous minds and strong personalities. Methods of recruitment, training, grading, promotion and remuneration are of importance as they contribute to this primary purpose. The satisfaction of this end indeed offers the only adequate safeguard against incompetence or corruption in the public service, and is accordingly an essential factor in the redemption of the politician from his low position in public esteem and in the restoration of confidence in democratic institutions.

Among the factors which promote the supply of administrators of the requisite quality, recruitment on a wider basis is essential, and for this reason the Committee insists not merely that local authorities should draw their professional and technical officers from all available sources, whether within the service or without, but also that difficulties in the way of recruiting university graduates without technical qualifications must be overcome. No source of supply of the rare and invaluable quality of leadership can safely be neglected, but it is equally important to remember that administrative powers can be developed by training and experience. The recommendations that deliberate efforts should be made to arrange to give promising young officers practical experience in administration and to encourage the study of the principles of public administration are vital.
The report is happily free from the suggestion that technical and scientific officers as a class are lacking in administrative ability. It is recognised that individuals of high professional or technical standing may be lacking in this quality; it is therefore the more important to recognise it and develop it where found. The report outlines principles which are fully as valid in industry or in the Civil Service as in local government service, whereby the requisite combination of technical knowledge, professional integrity and administrative capacity may be encouraged and brought to bear on the complex problems of to-day. Its recommendations for centralisation and unification of the service, like those bearing on promotion and remuneration, are significant so far as they contribute to the main purpose of creating a service which compares sufficiently well with those obtaining in private enterprise to secure a proportion of the ablest minds and strongest characters of each generation.

\section{Chemical Factors in Plant Growth}

Croissance des végétaux. Par Dr. Albert Demolon. (Principes d'agronomie, Tome 2.) Pp. ix +307 . (Paris: Libr. Dunod, 1934.)

$D^{R}$. DEMOLON is well known as one of the clearest thinkers and one of the most ingenious-minded among agricultural investigators. As chief scientific advisor to the French Ministry of Agriculture, he is kept in close touch with the practical problems of the French farmer, and as head of the research laboratories at Versailles he is equally closely associated with modern movements in science. In his earlier publication, "La Dynamique du Sol", he dealt with the formation and composition of soils and the changes occurring therein; in the present volume, which is by way of a continuation, he discusses the relations between the soil and the growing plant, the subject which as he truly points out is the foundation on which rests scientific agriculture.

In the first section of the book the author discusses the physical factors determining plant growth: the effects of light, of temperature, electricity and of various rays : also the amplitude of variations in yield due to meteorological conditions.

The greater part of the book deals with the chemical factors concerned in plant growth: the atmosphere, nitrogen and the mineral elements. The author sets out the facts clearly and discusses 
them with considerable penetration. He has the happy power, common to the best French writers, of choosing the words that best express his ideas, and of saying what he has to say clearly, tersely and accurately.

A useful summary is given of the part played by mineral elements other than the nitrogen, phosphorus and potassium which for long were the only substances considered to have fertiliser value. The standard fertilisers for many years past have in point of fact supplied other elements : superphosphate contains about 50 per cent of gypsum; the usual potassic fertilisers contain sodium or magnesium or both ; basic slag contains iron, manganese and other elements. In ordinary practice, therefore, farmers have been adding compounds of calcium, magnesium, sodium, iron, manganese, sulphur and chlorine along with the nitrogen, potassium and phosphate. But with recent improvements in technical chemistry, it is no longer necessary to use crude salts as fertiliser, and some of the new concentrated fertilisers attain a degree of purity hitherto unapproachable in agricultural practice. The question is now beginning to interest agricultural experts whether they should advise farmers to add deliberately to their soils some of the substances they have been adding only incidentally. It seems certain that in absence of these various elements, plant growth becomes abnormal and certain so-called physiological diseases are likely to be induced. This subject has been studied at the Institut Pasteur, Paris, at Rothamsted, the Waite Institute, Adelaide, various United States experiment stations and elsewhere. The author deals at some length with magnesium, which is now attracting some interest in France. Additions of manganese and boron to the soil seem to be necessary in certain cases, otherwise definite disease symptoms appear, but Dr. Demolon is less certain about the need for adding some of the other elements which refined water cultures show to be necessary.

Another subject now attracting much attention among agriculturists, and discussed at length by the author, is the possibility of toxin formation in soils. Some substances, hydrogen sulphide for example, are readily formed in anærobic conditions: others, such as excess of soluble salts, may be brought in from outside, for example, by sea floods. Plant roots were at one time supposed capable of excreting substances toxic to themselves if not to others, then the idea was dismissed; but Pickering's work at Woburn shows that there may be something in the old idea, and H. G. Thornton at Rothamsted has shown that lucerne seedlings certainly excrete something that stimulates bacterial development in the soil and that might therefore have some effect on other plants. The author summarises the facts clearly and concludes that no definite pronouncement can yet be made on this difficult subject.

After an interesting and succinct account of the relations of soil micro-organisms and plant growth, the author proceeds to summarise the present position in regard to the quantitative expression of plant growth phenomena by curves and equations. He discusses in the first instance the qualitative changes, the seedling stage, rapid vegetative growth, and maturation; these are not separated in point of time and at no time is the plant simply adding to its substance. The simpler formulæ put forward to express the relation between the supply of nutrients and the extent of growth are none of them satisfactory, though some of them may be sufficiently approximate to serve as a rough guide in fertiliser practice. Here too the author adopts a cautious reserve and prefers to await the result of further experiment before making too definite a pronouncement.

We can cordially recommend the volume to the student, both on account of its matter and of its presentation.

E. J. Russell.

\section{Celestial Mechanics}

Planetary Theory. By Prof. Ernest W. Brown and Prof. Clarence A. Shook. Pp. xii +302. (Cambridge: At the University Press, 1933.) 15s. net.

THERE are various definite theorems bearing 1 on the impossibility of solving the problem of three (or $n$ ) attracting bodies. What is certain, in a practical sense, is that no general solution is attainable in a form suitable for comparison with observations even for a limited interval of time.

Special methods have been devised for the two distinct types of motion which are present in the solar system, the motion of the planet and the motion of the satellite. In the latter case, when the satellite is identified with the moon, there results a problem of quite special character and quite extraordinary complexity. At the same time, it is essentially a single problem not lending itself naturally to piecemeal treatment. Adams, it is true, succeeded in discussing some of its leading features in an elementary way, besides obtaining 